\title{
Thyrohyoid Ligament
}

National Cancer Institute

\section{Source}

National Cancer Institute. Thyrohyoid Ligament. NCI Thesaurus. Code C33779.

Either of the two thyrohyoid lig aments (middle or lateral) that extend between the thyroid and the hyoid. 